\title{
Functional characterization of an invertase inhibitor gene involved in sucrose metabolism in tomato fruit*
}

\author{
Ning ZHANG ${ }^{\dagger}$, Jing JIANG ${ }^{\dagger \dagger}$, Yan-li YANG, Zhi-he WANG \\ (Key Laboratory of Protected Horticulture, Ministry of Education, College of Horticulture, \\ Shenyang Agricultural University, Shenyang 110866, China) \\ †E-mail: zhangningsyau@163.com; jj_syau@hotmail.com \\ Received Nov. 19, 2014; Revision accepted June 8, 2015; Crosschecked July 9, 2015
}

\begin{abstract}
In this study, we produced tomato plants overexpressing an invertase inhibitor gene (S/y-INH) from tomato, using a simple and efficient transient transformation system. Compared with control plants, the expression of Sly-INH was highly upregulated in S/y-INH overexpressing plants, as indicated by real-time polymerase chain reaction (PCR). Physiological analysis revealed that $S / y-I N H$ inhibited the activity of cell wall invertase (CWIN), which increased sugar accumulation in tomato fruit. Furthermore, Sly-INH mediated sucrose metabolism by regulating CWIN activity. Our results suggest that invertase activity is potentially regulated by the S/y-INH inhibitor at the post-translational level, and they demonstrate that the transient transformation system is an effective method for determining the functions of genes in tomato.
\end{abstract}

Key words: Invertase inhibitor, Fruit development, Transient transformation system, Solanum lycopersicum, Overexpression

doi: $10.1631 /$ jzus.B1400319

Document code: A

CLC number: R394-3

\section{Introduction}

Sucrose is an important transported sugar in higher plants, which is exported from the source tissues (leaves) via the phloem to various sink tissues (roots, stem, and reproductive organs). Cell wall invertase $(\mathrm{CWIN})$ is an important enzyme in determining the apoplastic sucrose:glucose ratio and regulating related signaling pathways (Hanson and Smeekens, 2009). Importantly, CWINs maintain sucrose concentration gradients, which are considered to be a driving force for sugar transport, partitioning, and storage between the photosynthetic source and sink tissues (Sturm, 1999; Chourey et al., 2006). The

\footnotetext{
¿Corresponding author

* Project supported by the National Natural Science Foundation of China (Nos. 31372054 and 30971999) and the State Key Laboratory of Plant Physiology and Biochemistry Open Project of China (No. SKLPPBKF1404)

(iD) ORCID: Jing JIANG, http://orcid.org/0000-0001-9203-9006

(c) Zhejiang University and Springer-Verlag Berlin Heidelberg 2015
}

activity of CWIN is strictly controlled at both the transcriptional and post-transcriptional levels (Huang et al., 2007). As a result of glycan decoration, the regulation of apoplasmic and vacuolar invertases may be highly dependent on post-translational mechanisms (Greiner et al., 2000; Rausch and Greiner, 2004; Tauzin et al., 2014). Recent studies have suggested that invertase activity may be subject to post-translational suppression by its inhibitory protein (Hothorn et al., 2004; Rausch and Greiner, 2004).

Biochemical characterization of plant invertase inhibitors was first performed in the 1960s (Schwimmer et al., 1961; Pressey, 1966), and the genes encoding these inhibitors were cloned three decades later (Greiner et al., 1998). These inhibitors have been identified in a variety of species, such as Arabidopsis, potato, tomato, and tobacco (Weil et al., 1994; Greiner et al., 1999; Bate et al., 2004; Link et al., 2004; Reca et al., 2008; Jin et al., 2009; Kusch et al., 2009; Brummell et al., 2011). The specificity of plant invertase inhibitors was identified in vitro 
through the use of recombinant proteins and in vivo using transgenic plants (Bate et al., 2004; Rausch and Greiner, 2004; Brummell et al., 2011). In tomato, silencing the expression of $I N H$ led to a $40 \%$ to $65 \%$ increase in apoplastic invertase activity in mature leaves, and the modified levels of invertase activity were specifically targeted to the apoplast (Jin et al., 2009). Moreover, modifying invertase activity via specific inhibitors can potentially govern the senescence process in plants to help attain maximum yields and desirable crop quality. However, the realization of this potential will require a more thorough understanding of the involvement of invertase inhibitors in the regulation of growth and development in other plant tissues.

Carbohydrate content and composition are important indicators of tomato fruit quality. Carbohydrates, which represent a major component of soluble solids, greatly contribute to tomato processing quality (Davies and Hobson, 1981; Baxter et al., 2005). The tomato is an ideal species for the study of metabolism related to soluble carbohydrate accumulation because of the natural genetic variation in tomato and the well-developed genetic and physiological information about Solanum lycopersicum and related species. Fruit quality has increasingly been linked to the activity of invertase inhibitors. The formation of the invertase inhibitor complex may be an important mechanism in the control of invertase activity in vivo, subsequently affecting carbon partitioning and fruit development (Fridman et al., 2004; Hothorn et al., 2010). Therefore, altering the activity of invertase inhibitors may serve as a strategy to increase the sucrose content and quality of fruit.

The biological functionality of invertase inhibitors has largely been identified through in vitro assays using recombinant proteins (Greiner et al., 1998; Bate et al., 2004). In recent years, significant progress has been made in identifying and elucidating the involvement of invertase inhibitors in development and plant responses to various stimuli through the use of transgenic plants. Although some studies have examined the effects of silencing invertase inhibitor genes in various fruit tissues, few studies have examined the role(s) of these inhibitors through overexpressing invertase genes in vivo (McLaughlin and Boyer, 2004; Jin et al., 2009). Overexpressing endogenous invertase inhibitors in fruits will provide useful information about these proteins, which play important roles in the complex metabolic networks of plants, especially with regard to governing carbon allocation and fruit development. In this study, we selected tomato fruit as a model plant that undergoes fleshy fruit development. To study the role of invertase inhibitors in fruits, an invertase inhibitor complementary DNA (cDNA) from tomato, Sly-INH, was introduced into tomato via Agrobacteriummediated transient expression of a construct containing an expression carrier inhibitor. The results help to elucidate the effect of Sly-INH expression and invertase activity on tomato fruit development.

\section{Materials and methods}

\subsection{Plant materials}

Tomato seeds (Micro-Tom) were surface sterilized with $0.5 \%(5 \mathrm{~g} / \mathrm{L})$ sodium hypochlorite, rinsed with water, and germinated for $3 \mathrm{~d}$ in the dark at $25{ }^{\circ} \mathrm{C}$. Uniformly germinated seedlings were transferred to seedling trays containing growth medium comprising 1 part peat:1 part perlite: 1 part vermiculite $(\mathrm{v} / \mathrm{v} / \mathrm{v})$ and grown in a greenhouse under a 12-h day-night period with temperatures of $25^{\circ} \mathrm{C}$ during the day and $15{ }^{\circ} \mathrm{C}$ at night and with an irradiance of $300 \mu \mathrm{mol}$ photons $/\left(\mathrm{m}^{2} \cdot \mathrm{s}\right)$. The relative humidity varied, averaging $80 \%$.

\subsection{Plasmid construction and plant transformation}

A fruit-specific overexpression construct for Sly-INH was produced by cloning the respective full-length cDNA into pCAMBIA1300 downstream of the 2A11 promoter. Full-length Sly-INH cDNA was cloned by polymerase chain reaction (PCR) using the following primers: forward 5'-ATGAAAATTTT GATTTTCCC-3' and reverse 5'-TTACAATAAATT TCTTACAA-3'.

Agroinjection was performed as described by Orzaez et al. (2006). Tomato fruits (S. lycopersicum cv. Micro-Tom) at 22 days after flowering (DAF) were injected with a maximum of $600 \mu \mathrm{l}$ agroinjection solution into mature green tomatoes. When some drops of infiltration solution appeared in the hydathodes at the tips of sepals, the fruits were determined to be fully infiltrated. Completely infiltrated fruits were used in the experiments. 


\subsection{Determination of soluble sugar and starch levels}

The contents of fruit discs $\left(0.5 \mathrm{~cm}^{2}\right)$ were extracted by incubating the discs in $1.0 \mathrm{ml} 80 \%$ ethanol at $80{ }^{\circ} \mathrm{C}$ for $60 \mathrm{~min}$ and centrifuged at $4{ }^{\circ} \mathrm{C}$ for $5 \mathrm{~min}$ at $14000 \mathrm{r} / \mathrm{min}$. After they were transferred to new tubes, the cleared supernatants were evaporated to dryness at $40{ }^{\circ} \mathrm{C}$. The dry residue was resolved in $250 \mu \mathrm{l}$ of ultrapure water and used for soluble sugar analysis. Starch analysis was performed using the pellets derived from the centrifugation step. The materials were homogenized in $0.2 \mathrm{~mol} / \mathrm{L}$ potassium hydroxide and incubated at $95{ }^{\circ} \mathrm{C}$ for $1 \mathrm{~h}$. Then, the $\mathrm{pH}$ was adjusted to 5.5 with $1 \mathrm{~mol} / \mathrm{L}$ acetic acid. Starch and soluble sugar assays were performed as described by Hajirezaei et al. (2000).

\subsection{Enzyme extraction and activity assays}

Fruit material samples $(100 \mathrm{mg})$ were homogenized in $50 \mathrm{mmol} / \mathrm{L}$ 4-(2-hydroxyethyl)-1-piperazineethanesulfonic acid (HEPES) buffer $(10 \mathrm{mmol} / \mathrm{L}$ magnesium chloride, $2.5 \mathrm{mmol} / \mathrm{L}$ dithiothreitol, $1 \mathrm{mmol} / \mathrm{L}$ ethylenediaminetetraacetic acid (EDTA), $10 \mathrm{mmol} / \mathrm{L}$ ascorbic acid, and 5\% polyvinylpyrrolidone, $\mathrm{pH}$ 7.5). The homogenates were centrifuged for $20 \mathrm{~min}$ at $12000 \mathrm{r} / \mathrm{min}$ at $4{ }^{\circ} \mathrm{C}$. An aliquot of the resulting supernatant was desalted through Sephadex G-25 (medium), equilibrated and used for the various assays. Neutral invertase (NI), sucrose synthase (SS), and sucrose phosphate synthase (SPS) activities were determined as described by Zrenner et al. (1995). CWIN and cytoplasmic invertase (CIN) activities were enzymatically assayed according to Gibon et al. (2004) and Tomlinson et al. (2004).

\subsection{RNA extraction and quantification}

Total RNA (1 g) was extracted from specified fruit tissues using a TIANGEN RNAprep pure plant kit (TIANGEN, Beijing, China) according to the manufacturer's instructions. First-strand cDNA synthesis of $1 \mu \mathrm{g}$ of RNA in a final volume of $20 \mu \mathrm{l}$ was performed using Moloney Murine Leukemia Virus Reverse Transcriptase, Point Mutant RNase H Minus (Promega, Beijing, China) following the manufacturer's protocol using oligo $(\mathrm{dT})_{18}$ primer. The expressions of LIN5, LIN6, LIN7, LIN8, TIV1, and INH were examined by real-time quantitative reverse transcription PCR (qRT-PCR) using the fluorescent intercalating dye
SYBR Green in an iCycler detection system (Bio-Rad; http://www.bio-rad.com) following the protocol of Schaarschmidt et al. (2006). The comparative $C_{\mathrm{T}}$ method was performed for relative quantification of the target gene expression levels. The next primers used were as follows: for analysis of LIN5 transcript levels (GenBank accession No. AJ272304), forward 5'-AAAGGGATCTCAGCATCACAGG-3', reverse 5'-CGTCTTGGGCATATAGGTCAGC-3'; for LIN6 (GenBank accession No. AF506006), forward 5'-AT CAAGCCCGATAACAATCCA-3', reverse 5'-CCTCA CACTCCCAACCAATACTC-3'; for LIN7 (GenBank accession No. AF506006), forward 5'-TTTGGTGCT GGTGGAAAGACA-3', reverse 5'-GGCTCCGTTC CGTTGTTAAAC-3'; for LIN8 (GenBank accession No. AF506007), forward 5'-AAGGATGGGCGGG AATACA-3', reverse 5'-GGCCTGTGCTGGTGTGA TT-3'; for TIV1 (GenBank accession No. AF506007), forward 5'-AGGACTTTAGAGACCCGACTAC-3', reverse 5'-GCAGCACTCCATCCAATAGC-3'; for Sly-INH (GenBank accession No. AJ010943), forward 5'-GTATGCCAGAAGCATTAGAAGCA-3', reverse 5'-GCATCACCAGAAGAACCAACC-3'. To normalize gene expression levels (to eliminate differences in the efficiency of cDNA synthesis), the transcript levels of the constitutively expressed Actin gene in tomato (XM 004249818) were measured using the following primers: forward 5'-TGTCCCTATTTACGAGGGT TATGC-3'; reverse 5'-AGTTAAATCACGACCAG CAAGAT- 3 '.

\subsection{Statistical analysis}

All agroinjection experiments were arranged in a completely randomized split-plot design with three replicates of 30 tomato plants each. Each extract was measured twice, and at least three replications were performed per analysis. For enzyme activity and sugar content assays, each biological replicate was composed of three technical replicates. Each experiment was repeated at least three times, and similar results were obtained. One representative set of data is described here from those that were carried out, and significant differences between the mean values among treatments were determined according to Tukey's Least Significant Difference test $(P<0.05)$ using analysis of variance (ANOVA; SPSS 11.0, Chicago, IL, USA). The standard errors (SEs) of the means were also calculated and are presented in the graphs as error bars. 


\section{Results}

\subsection{Agroinjection of tomato fruit tissues}

To assess the physiological role of Sly-INH in tomato fruit, we produced a $S l y-I N H$ overexpression construct harboring this gene driven by the fruitspecific 2A11 promoter. We introduced this plasmid into tomato via Agrobacterium tumefaciens-mediated fruit injection, as described by Orzaez et al. (2006), and measured the levels of Sly-INH transcript by qRT-PCR (Fig. 1).

As shown in Fig. 1, Sly-INH exhibited a tissuespecific expression pattern in p1300-2A11-INHagroinjected tomato fruits, with maximum expression observed in the pericarp, followed by the pectinic placenta and dissepiments, perhaps because these structures form a diffusion barrier in the apoplastic network of the fruit. These results indicate that Sly-INH can be effectively expressed in fruit tissues via agroinjection. Notably, the relative expression of Sly-INH in sepals was significantly different in tomato fruit agroinjected with EHA105 containing p1300-2A11-INH plasmid (OE) plants versus the controls, and a significant reduction in INH expression was observed after $5 \mathrm{~d}$, most likely because the infiltration solution in the hydathodes at the tips of sepals elicited $S l y-I N H$ gene silencing. Further studies are needed to determine whether the expression of $S l y-I N H$ is regulated via different routes.

\subsection{Activity of sugar metabolism-related enzymes}

After agroinjection of tomato fruits with EHA105 bacterial solution, CWIN activity in each part of the fruit was altered. The activity of this enzyme was slightly higher than that of uninjected fruit, while CIN, NI, SS, and SPS activities were not significantly altered (Figs. 2 and 3). These results may be because Agrobacterium infection triggers a defense response in the plant, and CWIN activity is related to stress. By contrast, CWIN activity was observably reduced in plants transformed with p1300-2A11-Sly-INH compared with the control. A remarkable inhibition of CWIN activity was observed in Sly-INH OE tomato fruits, especially in sepals and dissepiments, at $3 \mathrm{~d}$ after injection, with CWIN activity decreasing by $58.8 \%$ and $30.4 \%$, respectively. From 0 to $5 \mathrm{~d}$ after injection, CWIN activity decreased by $75.0 \%$ and $81.8 \%$ in sepals and dissepiments, respectively. In Sly-INH OE tomato fruits at $5 \mathrm{~d}$ after injection, CIN activity sharply increased in sepals, while CWIN activity decreased. It is worth noting that accurately comparing CWIN and tonoplast invertase (TIN) or CIN activity is difficult since CWIN activity is expressed based on cell-wall proteins whereas CIN and TIN activities are expressed on a soluble protein basis.

Analysis of the activities of other enzymes related to carbohydrate metabolism revealed an increase in the total activity of SS (when assayed in the

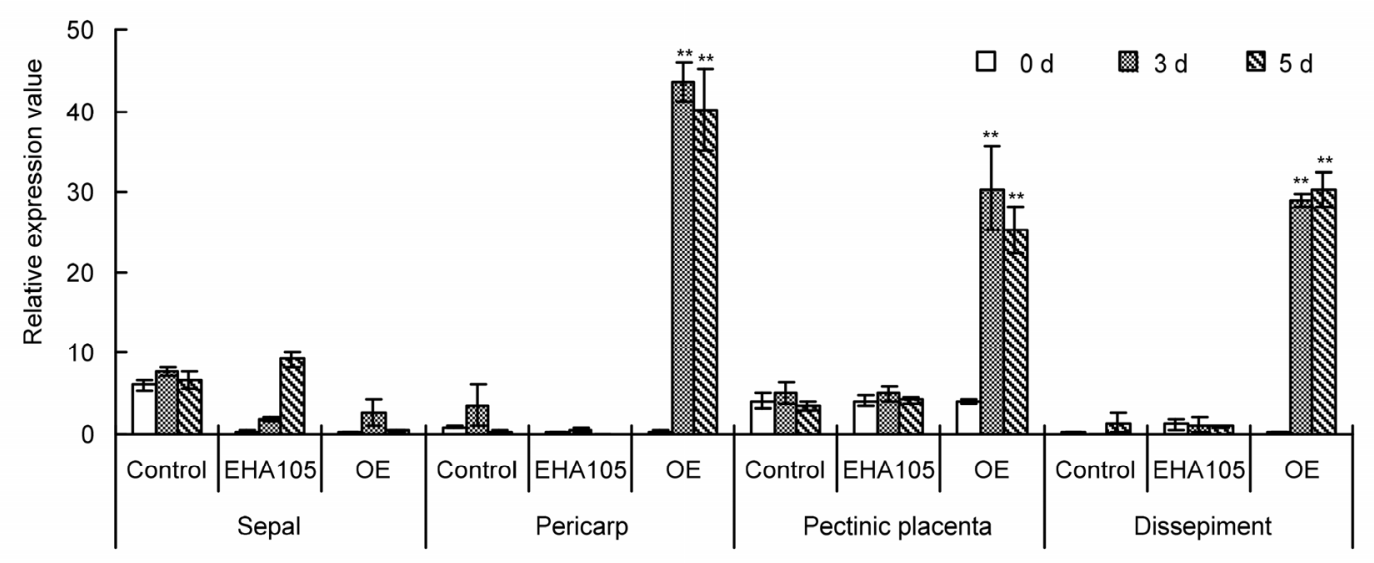

Fig. 1 Relative expression levels of $S l y-I N H$ in the sepal, pericarp, pectinic placenta, and dissepiment of Micro-Tom tomato fruits without agroinjection treatment (control), agroinjected with EHA105, or agroinjected with EHA105 containing p1300-2A11-INH plasmid $(\mathrm{OE})$ at 0,3 , and $5 \mathrm{~d}$, respectively

Data are expressed as mean $\pm \operatorname{SE}(n=3) .{ }^{* *} P<0.01$, compared with the control 

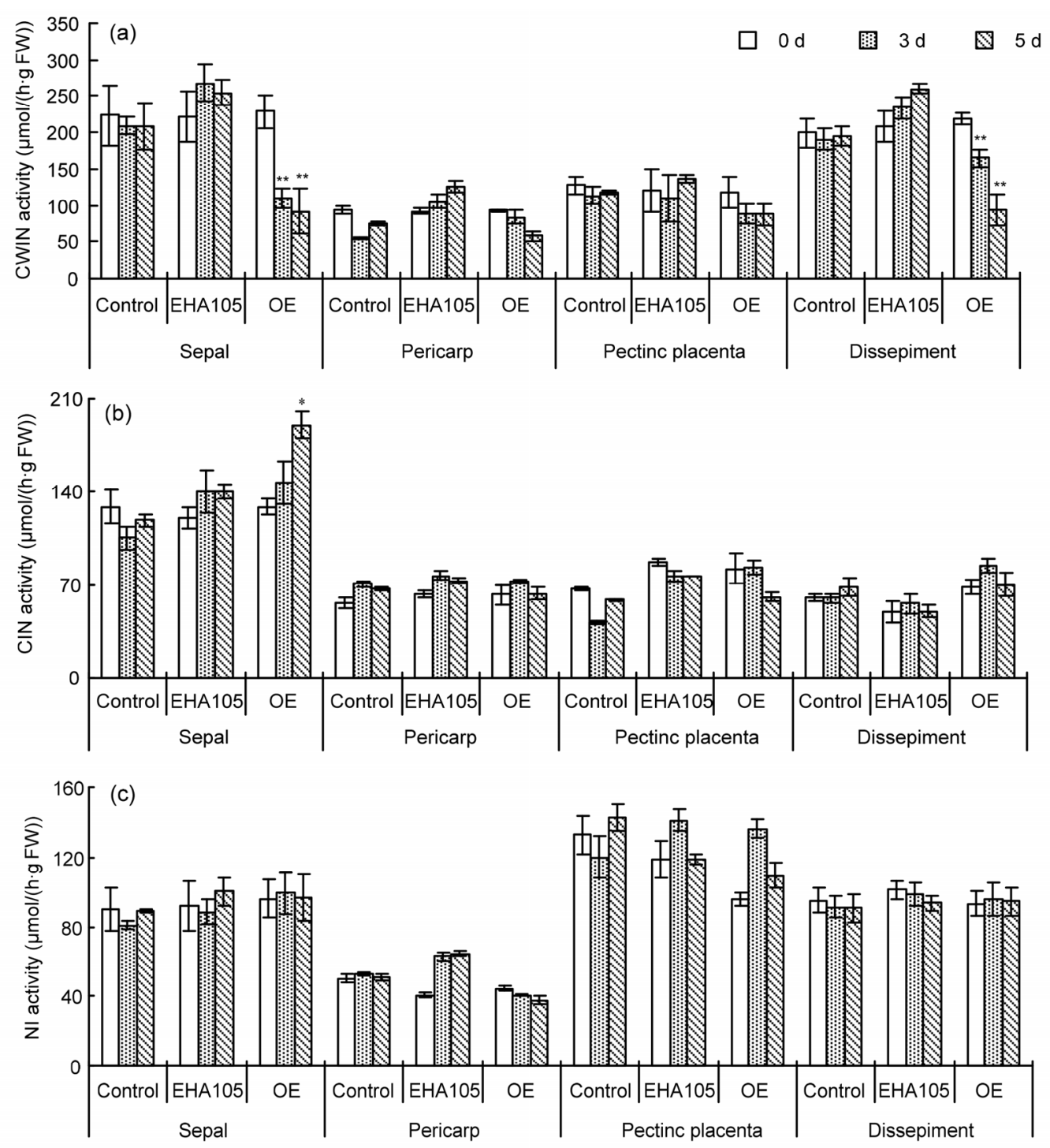

Fig. 2 Activities of invertase in the sepal, pericarp, pectinic placenta, and dissepiment of Micro-Tom tomato fruits without agroinjection treatment (control), agroinjected with EHA105, or agroinjected with EHA105 containing p1300-2A11-INH plasmid (OE) at 0,3 , and $5 \mathrm{~d}$, respectively

(a) Cell wall invertase (CWIN) activity; (b) Cytoplasmic invertase (CIN) activity; (c) Neutral invertase (NI) activity. Data are expressed as mean $\pm \mathrm{SE}(n=3) .{ }^{*} P<0.05,{ }^{* *} P<0.01$, compared with the control

direction of sucrose cleavage) and a decrease in the activity of SPS in the young fruits of plants most strongly overexpressing $S l y-I N H$ in the sepals (Fig. 3). This result suggests that injecting bacteria harboring a Sly-INH overexpression vector can reduce the activity of CWIN (Fig. 2). In Agrobacterium-mediated injected fruit, the expression of target genes can quickly be detected. A significant increase in the expression of the target gene in tomato fruit was detected at $3 \mathrm{~d}$ after injection.

\subsection{Relative expression levels and inhibition of sucrose invertase family genes}

To demonstrate that the reduction in CWIN expression resulted from a specific reduction in invertase expression, we examined the relative expression levels of CWIN family genes in fruit (Fig. 4). The tomato CWIN gene family includes $\operatorname{Lin} 5, \operatorname{Lin} 6, \operatorname{Lin} 7$, and Lin8. In pectinic placenta, the expression level of Lin5 was high, while there was no significant 

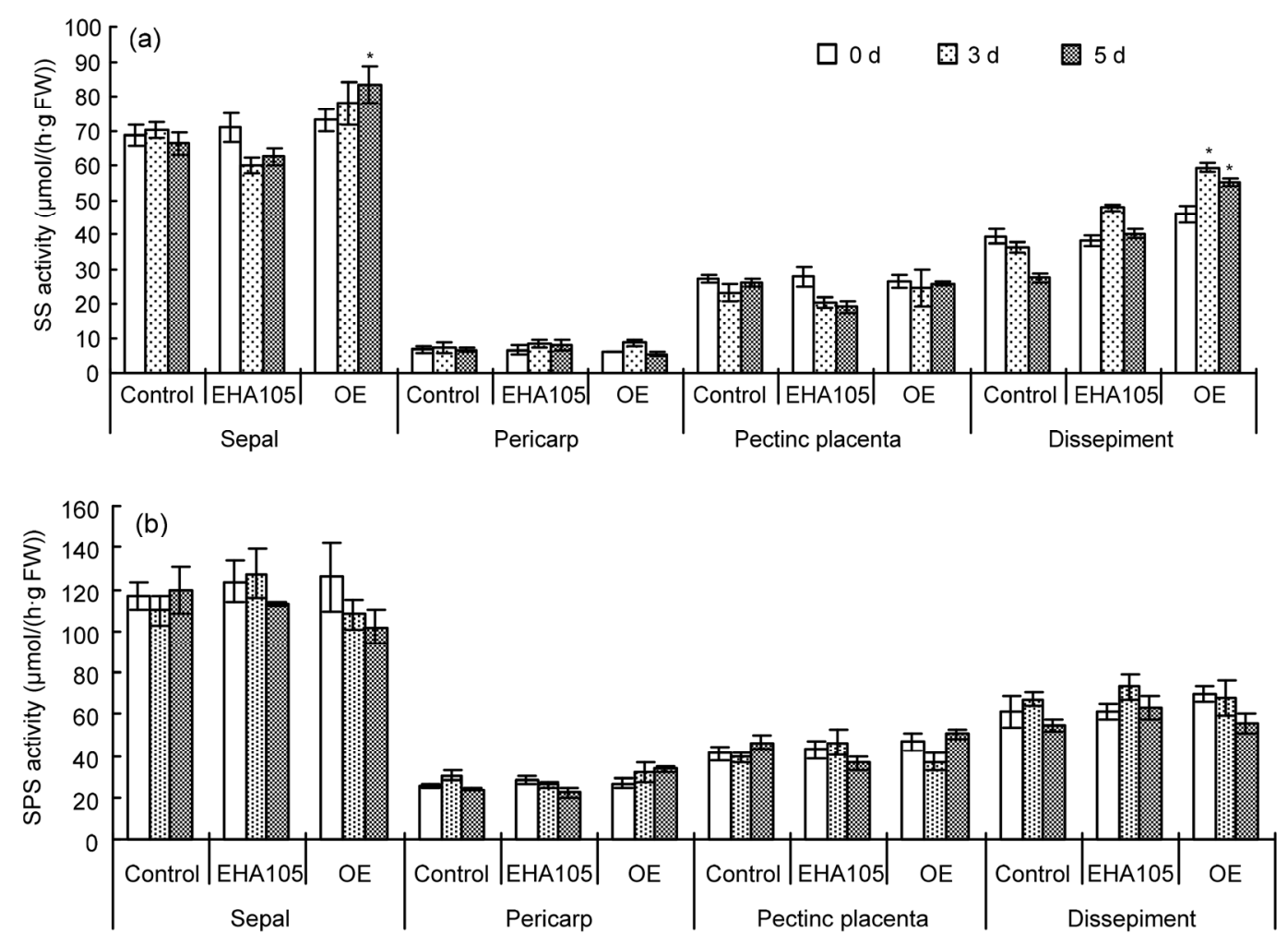

Fig. 3 Activities of sucrose synthase (SS) and sucrose phosphate synthase (SPS) in the sepal, pericarp, pectinic placenta, and dissepiment of Micro-Tom tomato fruits without agroinjection treatment (control), agroinjected with EHA105, or agroinjected with EHA105 containing p1300-2A11-INH plasmid (OE) at 0, 3, and 5 d, respectively

(a) SS activity; (b) SPS activity. Data are expressed as mean $\pm \operatorname{SE}(n=3) .{ }^{*} P<0.05$, compared with the control

expression in other parts of the fruit. Lin6 was mainly expressed in sepals, while $\operatorname{Lin} 7$ and $\operatorname{Lin} 8$ were not significantly expressed in any part of the tomato fruit examined. At 3 and $5 \mathrm{~d}$ after injection with bacteria harboring the Sly-INH overexpression vector, the expression of CWIN genes was not obviously affected. Interestingly, previous qRT-PCR analysis revealed no changes in the expression of $\operatorname{Lin} 7$ or the closest homolog Lin5 in transgenic tomato fruits subjected to agroinjection (Godt and Roitsch, 1997; Fridman and Zamir, 2003). Moreover, the expression of vacuolar invertase gene TIVI in the Sly-INH overexpression lines was not obviously altered compared with the control (Fig. 5).

\subsection{Carbohydrate composition and content}

To investigate the consequences of reduced fruit CWIN activity on carbohydrate metabolism, we measured the levels of soluble sugars and starch in fruits in the three treatment groups. Tomato fruits primarily contain glucose, fructose, and sucrose, which largely affect the flavor and quality of the fruit. Starch is an important storage material in plants, as starch that accumulates during early fruit development is stored and serves as a carbon source for subsequent sugar synthesis. Developing fruits represent strong sinks for sugars during fruit development. After agroinjection of tomato fruits, reduced CWIN activity caused an approximately 50\% decrease in starch contents compared with the control fruits, especially in sepals, pectinic placentas, and dissepiment (Fig. 6). While the amounts of glucose and fructose decreased slightly in injected fruits, sucrose levels increased approximately two-fold in injected fruits compared with controls. By contrast, there were no significant differences in carbohydrate contents between control fruits and fruits agroinjected with EHA105 (Fig. 6). 

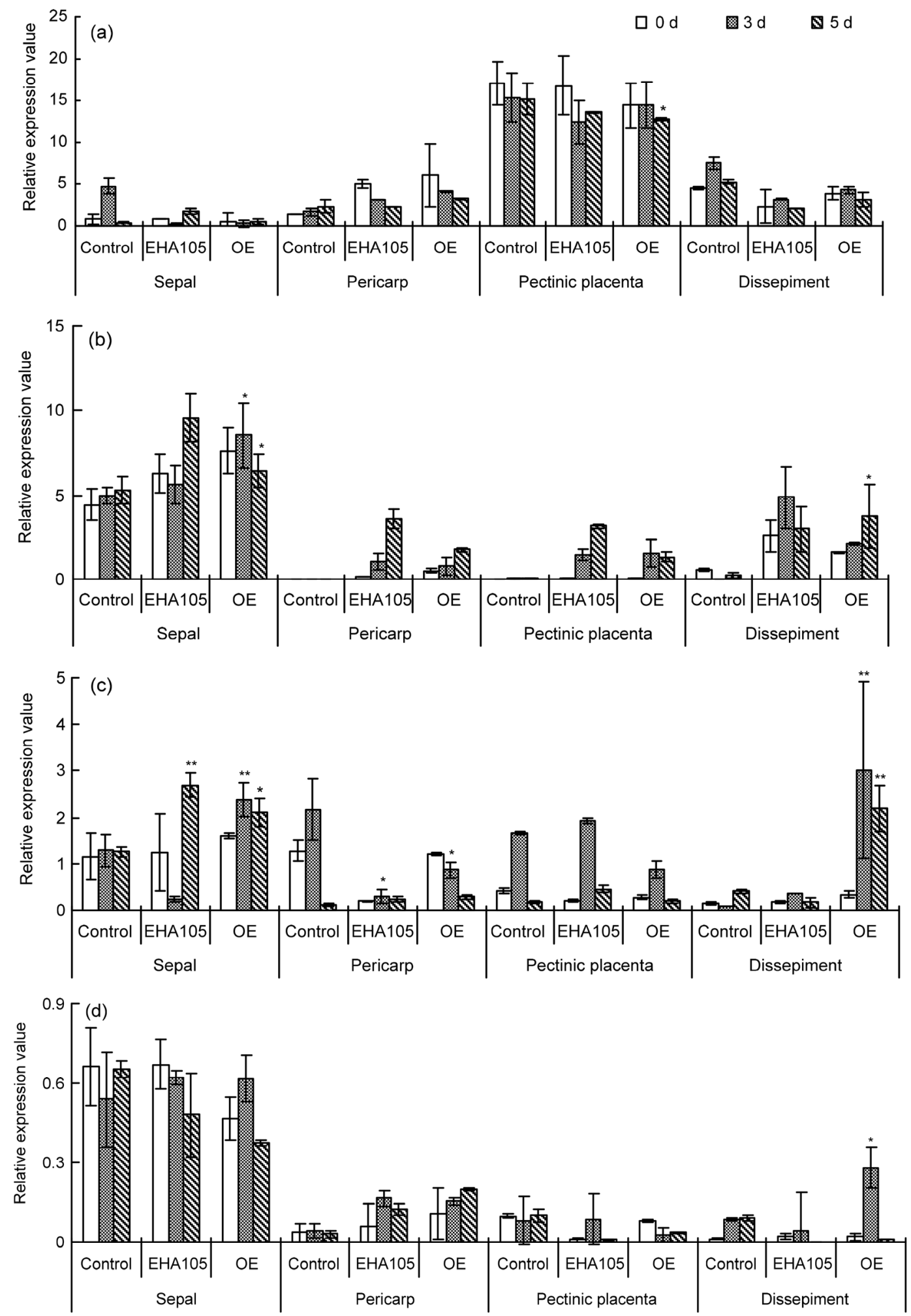

Fig. 4 Relative expression levels of cell wall invertase $(C W I N)$ gene families in the sepal, pericarp, pectinic placenta, and dissepiment of Micro-Tom tomato fruits without agroinjection treatment (control), agroinjected with EHA105, or agroinjected with EHA105 containing p1300-2A11-INH plasmid (OE) at 0, 3, and $5 \mathrm{~d}$, respectively

(a) Relative expression value of LIN5; (b) Relative expression value of LIN6; (c) Relative expression value of LIN7;

(d) Relative expression value of $L I N 8$. Data are expressed as mean $\pm \operatorname{SE}(n=3) .{ }^{*} P<0.05,{ }^{* *} P<0.01$, compared with the control 


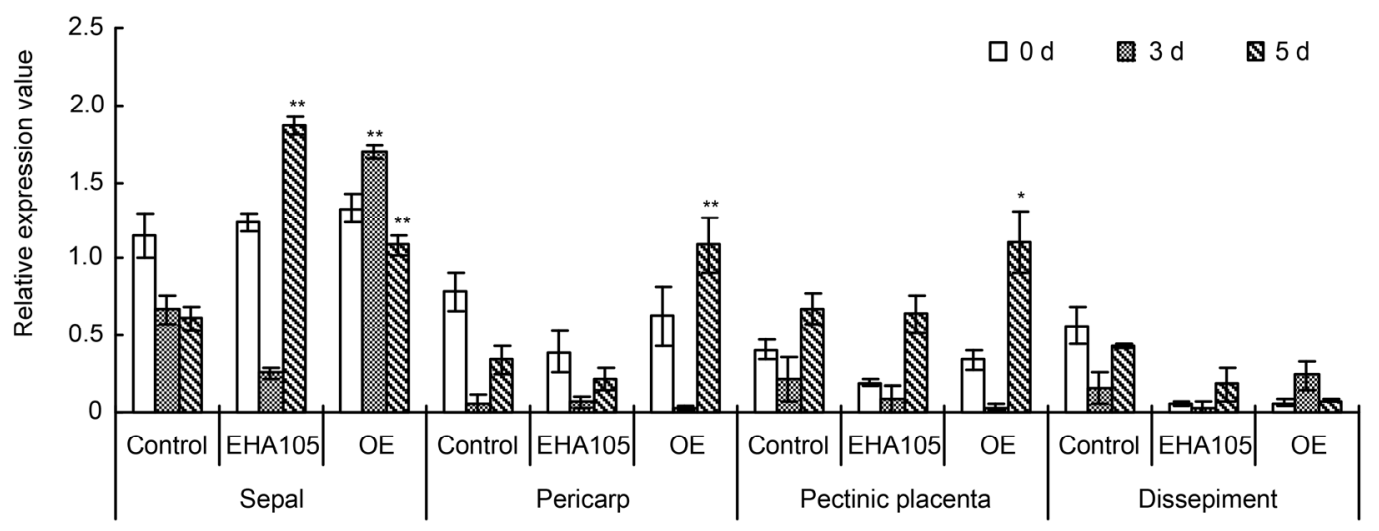

Fig. 5 Relative expression levels of vacuolar invertase TIV1 in the sepal, pericarp, pectinic placenta, and dissepiment of Micro-Tom tomato fruits without agroinjection treatment (control), agroinjected with EHA105, or agroinjected with EHA105 containing p1300-2A11-INH plasmid (OE) at 0,3 , and $5 \mathrm{~d}$, respectively Data are expressed as mean $\pm \operatorname{SE}(n=3) .{ }^{*} P<0.05,{ }^{* *} P<0.01$, compared with the control

\section{Discussion}

A. tumefaciens-mediated transient transformation is a simple, quick method that avoids the tedious process of tissue culture (Janssen and Gardner, 1990; Kapila et al., 1997). Most transferred DNA (T-DNA) that enters plant cells is not integrated into the plant genome but is instead temporarily stored in the nucleus, with a high copy number. Position effects and gene silencing have no effect on transient gene expression (Kapila et al., 1997; Wroblewski et al., 2005). In addition, traditional transformation systems require the use of antibiotics or other marker genes for initial screening; even so, false-positive plants are often selected, complicating analysis of test results. The agroinjection transformation system does not require the use of marker genes, avoiding the safety factor of antibiotics and transgenes and enabling the use of smaller vectors to transform larger fragments or more genes. Although agroinjection has many advantages, this method has certain limitations that should be considered when designing experiments. For example, its application is limited by the requirement to use only $A$. tumefaciens and similar species. Moreover, overexpression may affect the function and orientation of the gene product, and the stability is poor. In the current study, overexpression of Sly-INH has an inhibitory effect on apoplasmic invertase activity in tomato. The results suggest that at 3 to $5 \mathrm{~d}$ after $\mathrm{Ag}$ robacterium infection, high levels of expression of the transgenic product could be detected. Ripe fruits of commercial tomato variants are a good source of glucose and fructose (at equimolar concentrations), but they contain little sucrose (Klee and Giovannoni, 2011) owing to the effects of cell wall-bound and vacuolar invertases on fruit sink strength (Yelle et al., 1991; Klann et al., 1996; Jin et al., 2009; Zanor et al., 2009). In the current study, in Micro-Tom tomato injected with blank bacterial solution (EHA105), invertase activity in all parts of the fruit increased slightly, perhaps because the defense response triggered by Agrobacterium infection increased CWIN activity. This result is consistent with previous findings (Roitsch et al., 2003). After pathogen injection, the hexose content rapidly increases in plants, as hexose functions in the host defense response against pathogens (Herbers et al., 1996; Biemelt and Sonnewald, 2006). Scharte et al. (2005) found that during the early defense process in tobacco leaves injected with tobacco mosaic virus, CWIN is rapidly induced. The induction of CWIN is assumed to favor sink development, enabling the pathogen to withdraw carbohydrates for its nutrition. In addition, the levels of hexoses formed via CWIN activity increase to support defense responses. In the current study, the reduced invertase activity in Sly-INH-overexpressing tomato tissues resulted in reduced hexose and starch levels and increased sucrose levels (Fig. 6). These findings demonstrate that the activation of metabolic carbohydrate fluxes maintains the balance between starch and sucrose metabolism. 

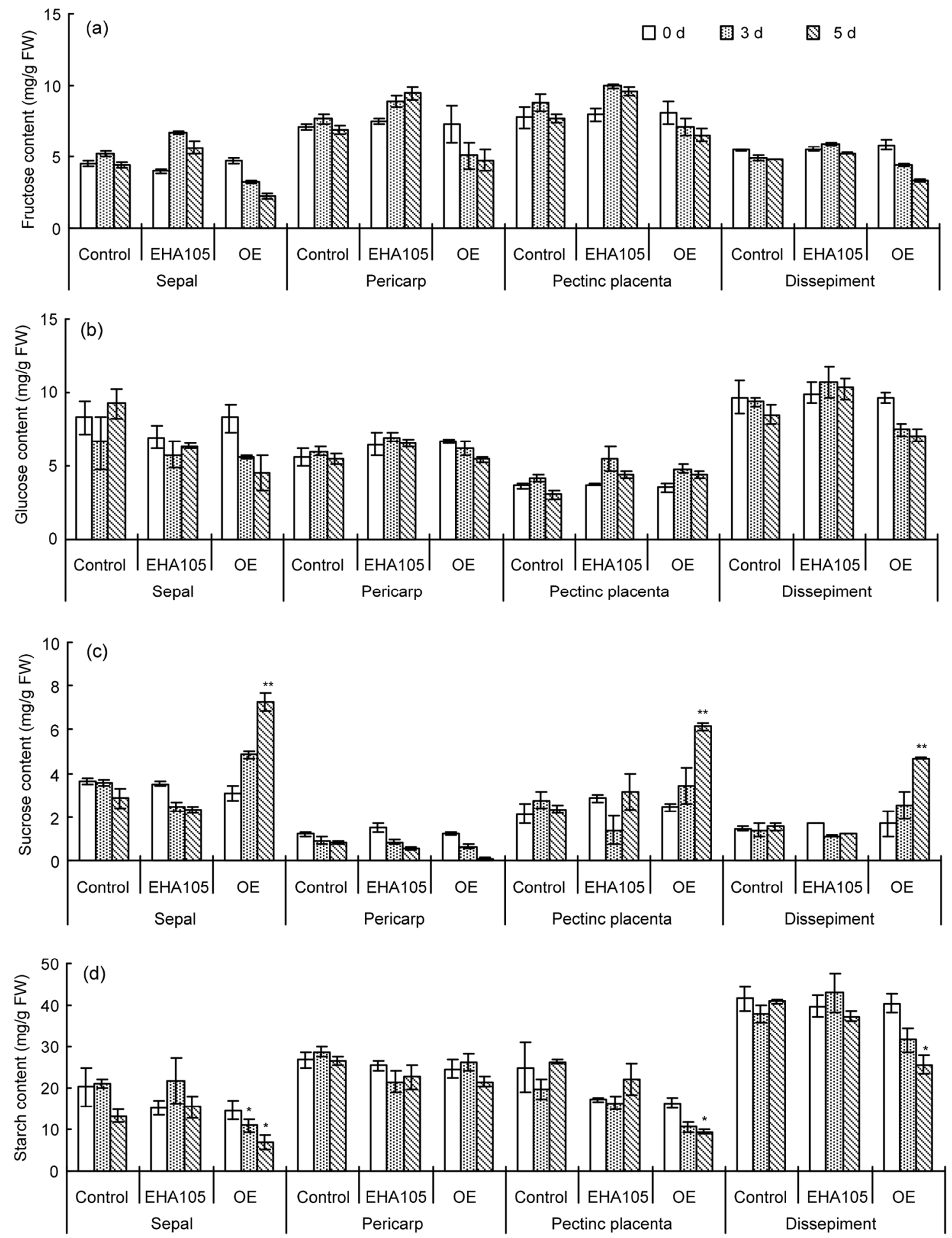

Fig. 6 Carbohydrate contents in different parts of Micro-Tom tomato fruits without agroinjection treatment (control), agroinjected with EHA105, or agroinjected with EHA105 containing p1300-2A11-INH plasmid $(\mathrm{OE})$ at 0,3 , and $5 \mathrm{~d}$, respectively

(a) Fructose content; (b) Glucose content; (c) Sucrose content; (d) Starch content. Data are expressed as mean $\pm \mathrm{SE}(n=3)$. ${ }^{*} P<0.05,{ }^{* *} P<0.01$, compared with the control 
Recently, a number of related studies have shown that $I N H$ inhibits invertase activity in vitro (Greiner et al., 1998). However, these studies, which used heterologous expression systems, did not elucidate the function of the endogenous $I N H$ gene. Jin et al. (2009) found that inhibiting the expression of $I N H$ in tomato increased the activity of CWIN $40 \%-65 \%$ in mature leaves. In mature leaves, fruits, and seeds, inhibiting the expression of $S l y-I N H$ has an effect on the contents of INV mRNA. In the current study, CWIN activity decreased in sepals, pericarp, and pectinic placenta in tomato fruit after injection with $S l y-I N H$, especially in sepals and dissepiment, whereas the activities of other sugar metabolismrelated enzymes remained unchanged. These findings indicate that overexpression of $S l y-I N H$ inhibits the activity of apoplasmic invertase in developing tomato fruit, which increases fruit sucrose levels.

Emerging evidence indicates that CWIN activity is tightly controlled at both the transcriptional and post-transcriptional levels (Huang et al., 2007). Invertase activity may be subject to post-translational suppression by its inhibitory protein (Hothorn et al., 2004; Rausch and Greiner, 2004; Jin et al., 2009). Our results suggest that Agrobacterium-mediated fruit injection greatly affected the expression of the target gene Sly-INH but had no effect on the transcription levels of genes in the invertase gene family (Fig. 4). However, physiological analysis indicated that CWIN activity was inhibited in these fruits. Taken together, these results suggest that the inhibitor Sly-INH regulates the activity of CWIN at the post-translational level. This finding is in accordance with previous invertase structural analysis (Jin et al., 2009; Hothorn et al., 2010).

Notably, the relative expression of $S l y-I N H$ was lower in sepals after injection compared with the control (Fig. 1), while reduced CWIN activity was evident in the sepals of OE plants (Fig. 2). These results raise the possibility that the reduced CWIN activity in 5-d sepals might have been due to different routes in the regulation of the inhibitory effect of Sly-INH against CWIN. For example, a recent sitedirected mutagenesis study showed that the presence of defective CWIN increased the inhibitory effect of INHs on CWIN activity (le Roy et al., 2013; Palmer et al., 2015).

\section{Conclusions}

This study demonstrates that CWIN and CIN exist in glycosylated form and are relatively stable, suggesting that the activities of these two invertases largely depend on post-translational regulation. The results suggest that the expression of Sly-INH increased significantly at $3 \mathrm{~d}$ after injection, while CWIN activity decreased significantly. These results demonstrate that the invertase inhibitor Sly-INH has the potential to regulate CWIN activity at the posttranslational level.

\section{Compliance with ethics guidelines}

Ning ZHANG, Jing JIANG, Yan-li YANG, and Zhi-he WANG declare that they have no conflict of interest.

This article does not contain any studies with human or animal subjects performed by any of the authors.

\section{References}

Bate, N.J., Niu, X.P., Wang, Y.W., et al., 2004. An invertase inhibitor from maize localizes to the embryo surrounding region during early kernel development. Plant Physiol., 134(1):246-254. [doi:10.1104/pp.103.027466]

Baxter, C., Carrari, F., Bauke, A., et al., 2005. Fruit carbohydrate metabolism in an introgression line of tomato with increased fruit soluble solids. Plant Cell Physiol., 46(3): 425-437. [doi:10.1093/pcp/pci040]

Biemelt, S., Sonnewald, U., 2006. Plant-microbe interactions to probe regulation of plant carbon metabolism. J. Plant Physiol., 163(3):307-318. [doi:10.1016/j.jplph.2005.10.011]

Brummell, D.A., Chen, R.K., Harris, J.C., et al., 2011. Induction of vacuolar invertase inhibitor mRNA in potato tubers contributes to cold-induced sweetening resistance and includes spliced hybrid mRNA variants. J. Exp. Bot., 62(10):3519-3534. [doi:10.1093/jxb/err043]

Chourey, P.S., Jain, M., Li, Q.B., et al., 2006. Genetic control of cell wall invertases in developing endosperm of maize. Planta, 223(2):159-167. [doi:10.1007/s00425-005-0039-5]

Davies, J.N., Hobson, G.E., 1981. The constituents of the tomato fruit - the influence of environment, nutrition, and genotype. Crit. Rev. Food Sci. Nutr., 15(3):205-280. [doi:10.1080/10408398109527317]

Fridman, E., Zamir, D., 2003. Functional divergence of a syntenic invertase gene family in tomato, potato, and Arabidopsis. Plant Physiol., 131(2):603-609. [doi:10. 1104/pp.014431]

Fridman, E., Carrari, F., Liu, Y.S., et al., 2004. Zooming in on a quantitative trait for tomato yield using interspecific introgressions. Science, 305(5691):1786-1789. [doi:10. 1126/science.1101666]

Gibon, Y., Blaesing, O.E., Hannemann, J., et al., 2004. A robot-based platform to measure multiple enzyme activities 
in Arabidopsis using a set of cycling assays: comparison of changes of enzyme activities and transcript levels during diurnal cycles and in prolonged darkness. Plant Cell, 16(12):3304-3325. [doi:10.1105/tpc.104.025973]

Godt, D.E., Roitsch, T., 1997. Regulation and tissue-specific distribution of mRNAs for three extracellular invertase isoenzymes of tomato suggests an important function in establishing and maintaining sink metabolism. Plant Physiol., 115(1):273-282. [doi:10.1104/pp.115.1.273]

Greiner, S., Krausgrill, S., Rausch, T., 1998. Cloning of a tobacco apoplasmic invertase inhibitor. Proof of function of the recombinant protein and expression analysis during plant development. Plant Physiol., 116(2):733-774. [doi: 10.1104/pp.116.2.733]

Greiner, S., Rausch, T., Sonnewald, U., et al., 1999. Ectopic expression of a tobacco invertase inhibitor homolog prevents cold-induced sweetening of potato tubers. Nat. Biotechnol., 17(7):708-711. [doi:10.1038/10924]

Greiner, S., Koster, U., Lauer, K., et al., 2000. Plant invertase inhibitors: expression in cell culture and during plant development. Aust. J. Plant Physiol., 27(9):807-814. [doi:10.1071/PP99171]

Hajirezaei, M.R., Takahata, Y., Trethewey, R.N., et al., 2000. Impact of elevated and apoplastic invertase activity on carbon metabolism during potato tuber development. $J$. Exp. Bot., 51(Suppl. 1):439-445. [doi:10.1093/jexbot/51. suppl_1.439]

Hanson, J., Smeekens, S., 2009. Sugar perception and signalingan update. Curr. Opin. Plant Biol., 12(5):562-567. [doi:10 1016/j.pbi.2009.07.014]

Herbers, K., Meuwly, P., Frommer, W.B., et al., 1996. Systemic acquired resistance mediated by the ectopic expression of invertase: possible hexose sensing in the secretory pathway. Plant Cell, 8(5):793-803. [doi:10.2307/ 3870282]

Hothorn, M., Wolf, S., Aloy, P., et al., 2004. Structural insights into the target specificity of plant invertase and pectin methylesterase inhibitory proteins. Plant Cell, 16(12): 3437-3447. [doi:10.1105/tpc.104.025684]

Hothorn, M., Ende, W.V., Lammensc, W., et al., 2010. Structural insights into the $\mathrm{pH}$-controlled targeting of plant cell wall invertase by a specific inhibitor protein. PNAS, 107(40):17427-17432. [doi:10.1073/pnas. 100448 1107]

Huang, L.F., Bocock, P.N., Davis, J.M., et al., 2007. Regulation of invertase: a suite of transcriptional and posttranscriptional mechanisms. Funct. Plant Biol., 34(6): 499-507. [doi:10.1071/FP06227]

Janssen, B.J., Gardner, R.C., 1990. Localized transient expression of GUS in leaf discs following cocultivation with Agrobacterium. Plant Mol. Biol., 14(1):61-72. [doi:10. 1007/BF00015655]

Jin, Y., Ni, D.A., Ruan, Y.L., 2009. Posttranslational elevation of cell wall invertase activity by silencing its inhibitor in tomato delays leaf senescence and increases seed weight and fruit hexose level. Plant Cell, 21(7):2072-2089. [doi:10.1105/tpc.108.063719]

Kapila, J., Rycke, R.D., van Montagu, M., 1997. An Agrobacterium-mediated transient gene expression system for intact leaves. Plant Sci., 122(1):101-108. [doi:10. 1016/S0168-9452(96)04541-4]

Klann, E.M., Hall, B., Bennett, A.B., 1996. Antisense acid invertase (TIVI) gene alters soluble sugar composition and size in tomato fruit. Plant Physiol., 112(3):1321-1330. [doi:10.1104/pp.112.3.1321]

Klee, H.J., Giovannoni, J.J., 2011. Genetics and control of tomato fruit ripening and quality attributes. Annu. Rev. Genet., 45(1):41-59. [doi:10.1146/annurev-genet-110410132507]

Kusch, U., Harms, K., Rausch, T., et al., 2009. Inhibitors of plant invertases do not affect the structurally related enzymes of fructan metabolism. New Phytol., 181(3): 601-612. [doi:10.1111/j.1469-8137.2008.02688.x]

le Roy, K., Vergauwen, R., Struyf, T., et al., 2013. Understanding the role of defective invertases in plants: tobacco Nin88 fails to degrade sucrose. Plant Physiol., 161(4): 1670-1681. [doi:10.1104/pp.112.209460]

Link, M., Rausch, T., Greiner, S., 2004. In Arabidopsis thali$a n a$, the invertase inhibitors AtC/VIF1 and 2 exhibit distinct target enzyme specificities and expression profiles. FEBS Lett., 573(1-3):105-109. [doi:10.1016/j.febslet.2004. 07.062]

McLaughlin, J.E., Boyer, J.S., 2004. Sugar-responsive gene expression, invertase activity, and senescence in aborting maize ovaries at low water potentials. Ann. Bot., 94(5): 675-689. [doi:10.1093/aob/mch193]

Orzaez, D., Sophie, M., Willemien, H., et al., 2006. Agroinjection of tomato fruits: a tool for rapid functional analysis of transgenes directly in fruit. Plant Physiol., 140(1):3-11. [doi:10.1104/pp.105.068221]

Palmer, W.M., Ru, L., Jin, Y., et al., 2015. Tomato ovaryto-fruit transition is characterized by a developmental shift of cell wall invertase and its inhibitor mRNAs from a dispersed expression to a phloem-specific pattern with the encoded proteins localized to sieve elements. Mol. Plant, 8(2):315-328. [doi:10.1016/j.molp.2014.12.019]

Pressey, R., 1966. Separation and properties of potato invertase and invertase inhibitor. Arch. Biochem. Biophys., 113(3):667-674. [doi:10.1016/0003-9861(66)90246-3]

Rausch, T., Greiner, S., 2004. Plant protein inhibitors of invertases. Biochim. Biophys. Acta, 1696(2):253-261. [doi: 10.1016/j.bbapap.2003.09.017]

Reca, I.B., Brutus, A., D'Avino, R., et al., 2008. Molecular cloning, expression and characterization of a novel apoplastic invertase inhibitor from tomato (Solanum lycopersicum) and its use to purify a vacuolar invertase. $B i$ ochimie, 90(11-12):1611-1623. [doi:10.1016/j.biochi.2008. 04.019]

Roitsch, T., Balibrea, M.E., Hofmann, M., et al., 2003. Extracellular invertase: key metabolic enzyme and PR protein. J. Exp. Bot., 54(382):513-524. [doi:10.1093/jxb/ $\operatorname{erg} 050]$

Schaarschmidt, S., Roitsch, T., Hause, B., 2006. Arbuscular mycorrhiza induces gene expression of the apoplastic 
invertase LIN6 in tomato (Lycopersicon esculentum) roots. J. Exp. Bot., 57(15):4015-4023. [doi:10.1093/jxb/ erl172]

Scharte, J., Schon, H., Weis, E., 2005. Photosynthesis and carbohydrate metabolism in tobacco leaves during an incompatible interaction with Phytophthora nicotianae. Plant Cell Environ., 28(11):1421-1435. [doi:10.1111/j. 1365-3040.2005.01380.x]

Schwimmer, S., Makower, R.U., Rorem, E.S., 1961. Invertase and invertase inhibitor in potato. Plant Physiol., 36(3): 313-316. [doi:10.1104/pp.36.3.313]

Sturm, A., 1999. Invertases: primary structures, functions, and roles in plant development and sucrose partitioning. Plant Physiol., 121(1):1-8. [doi:10.1104/pp.121.1.1]

Tauzin, A.S., Sulzenbacher, G., Lafond, M., et al., 2014. Functional characterization of a vacuolar invertase from Solanum lycopersicum: post-translational regulation by $\mathrm{N}$-glycosylation and a proteinaceous inhibitor. Biochimie, 101:39-49. [doi:10.1016/j.biochi.2013.12.013]

Tomlinson, K.L., McHugh, S., Labbe, H., et al., 2004. Evidence that the hexose-to-sucrose ratio does not control the switch to storage product accumulation in oilseeds: analysis of tobacco seed development and effects of overexpressing apoplastic invertase. J. Exp. Bot., 55(406): 2291-2303. [doi:10.1093/jxb/erh251]

Weil, M., Krausgrill, S., Schuster, A., et al., 1994. A 17-kDa Nicotiana tabacum cell-wall peptide acts as an in-vitro inhibitor of the cell-wall isoform of acid invertase. Planta, 193(3):438-445. [doi:10.1007/BF00201824]

Wroblewski, T., Tomczak, A., Michelmore, R., 2005. Optimization of Agrobacterium-mediated transient assays of gene expression in lettuce, tomato, and Arabidopsis. Plant Biotechnol. J., 3(2):259-273. [doi:10.1111/j.14677652.2005.00123.x]

Yelle, S., Chetelat, R.T., Dorais, M., et al., 1991. Sink metabolism in tomato fruit, genetic and biochemical analysis of sucrose accumulation. Plant Physiol., 95(4):1026-1035. [doi:10.1104/pp.95.4.1026]

Zanor, M.I., Osorio, S., Nunes-Nesi, A., et al., 2009. RNA interference of LIN5 in tomato confirms its role in controlling Brix content, uncovers the influence of sugars on the levels of fruit hormones, and demonstrates the importance of sucrose cleavage for normal fruit development and fertility. Plant Physiol., 150(3):1204-1218. [doi:10.1104/pp.109.136598]
Zrenner, R., Salanoubat, M., Willmitzer, L., et al., 1995. Evidence of the crucial role of sucrose synthase for sink strength using transgenic potato plants (Solanum tuberosum L.). Plant J., 7(1):97-107. [doi:10.1046/j.1365313X.1995.07010097.x]

\section{中文概要}

题 目: 转化酶抑制子调控番茄果实糖代谢的功能分析

目 的: 研究转化酶抑制子基因对番茄果实糖转运与积累 的影响, 并初步探讨其调控机制。

创新点: 首次在番茄果实瞬时表达系统中证明转化酶抑制 子可明显抑制细胞壁转化酶活性, 并且此抑制作 用是通过翻译后水平发挥作用。

方 法: 将 Micro-Tom 番茄分为对照组 (果实未注射农杆 菌及注射不含载体的空白农杆菌) 和实验组（果 实注射含有过表达转化酶抑制子基因的农杆 菌), 番茄果实分为薷片、中果肉、胶质胎座和 心室隔壁四个部位, 用实时定量聚合酶链式反应 （qRT-PCR）技术检测转化酶抑制子和转化酶基 因家族的表达变化, 利用比色法分别检测了蔗糖 代谢关键酶活性的变化, 用高效液相色谱检测果 实各部位果糖、葡萄糖和蔗糖的含量, 利用高氯 酸水解法测定淀粉的含量。

结 论: 利用农杆菌注射进行果实瞬时表达后果实各部位 的细胞壁转化酶活性受到明显抑制, 但转化酶基 因家族的转录水平表达变化不大, 果糖和葡萄糖 含量下降, 庶糖含量有所升高。这一结果表明 $S l y-I N H$ 基因主要是通过在翻译后水平对番茄细 胞壁转化酶进行调控, 进而影响番茄果实糖的组 成与含量。本研究从分子水平对转化酶抑制子及 其调控的转化酶基因家族进行了系统性研究, 这 为利用栽培手段调控植物体内转化酶的表达和 活性, 调节库组织的蔗糖的输入速率以及同化产 物的分配以改善品质提供依据与技术支持。

关键词: 转化酶抑制子; 果实发育; 瞬时表达体系; 过表 达; 番茄 